Jurnal Mandala Pharmacon Indonesia, Vol 6.No.1 Juni 2020

Avaiable online at www.jurnal-pharmaconmw.com/jmpi

p-ISSN : 2442-6032

$e$-ISSN : 2598-9979

\title{
Pengukuran Parameter Spesifik Dan Non Spesifik Ekstrak Etanol Daun Matoa (Pometia pinnata J.R \& G.Forst)
}

Fadillah Maryam, Burhanuddin Taebe, Deby Putrianti Toding

Sekolah Tinggi Ilmu Farmasi Makassar

\begin{abstract}
ABSTRAK
Tanaman matoa (Pometia pinnata J.R. \& G.Forst) telah dikenal memiliki banyak efek farmakologis dan digunakan sebagai obat tradisional. Salah satu dari tanaman matoa yang dimanfaatkan adalah daunnya yang berfungsi sebagai antibakteri, diuretik, analgesik dan lain-lain. Agar dapat dijadikan sebagai bahan baku obat tradisional maka perlu dilakukan standardisasi. Tujuan penelitian ini adalah untuk memperoleh nilai-nilai standar parameter spesifik dan non spesifik. Ekstrak etanol daun matoa diperoleh dengan cara ekstraksi metode maserasi menggunakan etanol $70 \%$ menghasilkan rendamen sebesar 12,98\%. Ekstrak yang dihasilkan merupakan ekstrak kering, berwarna coklat memiliki rasa pahit dan berbau khas serta mengandung metabolit sekunder berupa alkaloid, flavonoid, steroid, tanin dan saponin dengan pola kromatogram yang menunjukkan adanya beberapa noda dengan nilai $\mathrm{Rf}$ yang berbeda.
\end{abstract}

Kadar senyawa yang terlarut pada pelarut air sebesar $32,21 \%$, sedangkan kadar senyawa yang larut dalam etanol sebesar 38,56\%. Susut pengeringan sebesar 7,03\%. Bobot jenis ekstrak sebesar 0,9013\%. Kadar abu total sebesar 2,46\%, sedangkan kadar abu tidak larut asam sebesar 0,049\%. Kadar air ekstrak sebesar 5\%. Total cemaran bakteri sebanyak 7,8x10 4 koloni/g dan cemaran kapang sebesar $5,5 \times 10^{4}$ koloni/g. Berdasarkan hasil penelitian dapat dilihat beberapa parameter spesifik dan non spesifik memenuhi standar mutu yang telah ditetapkan.

Kata Kunci: Daun Matoa, Parameter Spesifik dan Non Spesifik

\section{Penulis Korespondensi :}

Fadillah Maryam

Sekolah Tinggi Ilmu Farmasi Makassar

E-mail : dilla.guerjel@yahoo.co.id

\section{PENDAHULUAN}

Indonesia merupakan salah satu negara dengan kekayaan hayati terbesar di dunia yang memiliki lebih dari 30.000 spesies tanaman tingkat tinggi. Hingga saat ini, tercatat 7000 spesies tanaman telah diketahui khasiatnya namun kurang dari 300 tanaman yang digunakan sebagai bahan baku industri farmasi secara regular. Sekitar 1000 jenis tanaman telah diidentifikasi dari aspek botani sistematik tumbuhan dengan baik (Saifuddin, dkk.,2011).
Salah satu tanaman yang dapat dimanfaatkan sebagai obat tradisional adalah matoa (Pometia pinnata J.R. \& G. Forst). Matoa merupakan jenis tanaman suku Sapindaceae yang tersebar di wilayah Asia Tenggara (Malaysia dan Indonesia) (Sudarmono, 2000). Tanaman ini telah dimanfaatkan oleh Bangsa Asia (Papua, Malaysia dan Indonesia) sebagai salah satu bahan obat tradisional yang diketahui mengandung golongan senyawa berupa flavonoid, tanin dan saponin (Dalimartha, 2005). 
Secara empiris tanaman matoa telah banyak digunakan dalam pengobatan di beberapa daerah. Daun matoa dapat digunakan sebagai obat demam, sakit kulit dan bengkak keseleo. Kulit pohon matoa juga dapat digunakan sebagai tuba ikan (Sangat et al, 2000).

Pada penelitian sebelumnya Rahimah et al. (2013) didapatkan senyawa golongan flavonoid dengan mengidentifikasikan senyawa dari isolat yang diperoleh dari daun matoa (Pometia pinnata J.R. \& G. Forst). Selain itu daun matoa juga mengandung saponin dan tanin (Variany, 1999). Di Malaysia, rebusan daun dan kulit kayu dipakai mandi untuk mengatasi demam. Masyarakat Fiji menggunakan ekstrak daun untuk menghitamkan rambut. Rendaman daun diair panas baik untuk mengobati disentri. Sedangkan influenza dan nyeri tulang sendi diobati dengan cara minum air perasan dari kulit kayu bagian dalam pohon matoa, (Suharno dan Tanjung, 2011).

Penelitian ini mengacu pada penelitian dan pengembangan tanaman berkhasiat obat. Standardisasi sangat penting dilakukan untuk mengembangkan obat dari bahan alam yang tersebar luas di Indonesia untuk menjamin mutu serta keamanan dari sediaan obat tersebut yang nantinya dapat dikembangkan menjadi fitofarmaka ataupun obat herbal terstandar.
Berdasarkan Keputusan Menteri Kesehatan RI No 55/Menkes/SK/1/200o, obat tradisional yang beredar di Indonesia harus memenuhi persyaratan mutu, keamanan dan kemanfaatannya (Depkes RI, 2000). Oleh karena itu, perlu dilakukan suatu penelitian pengukuran parameter spesifik ekstrak (organoleptis, pola kromatogram, macam-macam kandungan kimia, penetapan kadar sari larut air dan larut etanol) dan non spesifik (susut pengeringan, kadar abu total, kadar abu tidak larut asam, kadar air, bobot jenis dan cemaran mikroba) pada daun matoa untuk mengetahui secara ilmiah kandungan yang terdapat dalam daun matoa sebagai bahan baku tanaman obat serta manfaatnya dan untuk menjamin mutu dan keamanannya.

\section{METODE PENELITIAN}

\section{Alat dan Bahan}

Alat yang digunakan dalam penelitian ini yaitu : alat-alat gelas, autoklaf, cawan penguap, cawan petri, desikator, enkas, gegep, handscoon, hot plate, inkubator, kamera, krus porselin, LAF, Lampu UV, masker, oven, piknometer, tabung reaksi, tanur, termometer, timbangan analitik, dan toples kaca.

Bahan yang digunakan dalam penelitian ini yaitu : aquadest, asam asetat anhidrat, DMSO 10\%, etanol 95\% dan $70 \%$, eter, $\mathrm{FeCl}_{3}, \mathrm{HCl}$ pekat, $\mathrm{HCl} 2 \mathrm{~N}$, $\mathrm{H}_{2} \mathrm{SO}_{4} 10 \%, \mathrm{H}_{2} \mathrm{SO}_{4}$ pekat, kertas saring, kloroform, lempeng silika GF 254, NaCl, 
n-Heksan, Nutrient agar (NA), pereaksi mayer, wagner dan dragendroff, Potato Dextrose Agar (PDA), serbuk Mg, daun matoa (Pometia pinnata J.R. \& G. Forst) dan toluen.

\section{Pengolahan Sampel}

Diambil daun matoa kemudian dicuci dengan air mengalir. Kemudian dirajang dan dikeringkan dengan cara dianginanginkan langkah selanjutnya yaitu daun matoa disimpan dalam wadah kaca, tertutup rapat, terlindung dari sinar matahari serta pada suhu kamar.

\section{Pembuatan Ekstrak}

Simplisia daun matoa diekstraksi dengan metode maserasi menggunakan pelarut etanol 70\%. Sejumlah 400 gram daun matoa kering dimasukkan ke dalam wadah maserasi kemudian direndam dengan 4 liter pelarut etanol 70\% selama $3 \times 24$ jam dan dilakukan pengadukan sesekali. Saring, maserat berupa ekstrak cair dikumpulkan kemudian dilakukan proses remaserasi selama 2 x 24 jam dengan cara yang sama dan menggunakan pelarut yang baru. Setelah itu maserat diuapkan dengan cara diangin-anginkan hingga diperoleh ekstrak kering

\section{Pengujian Parameter Spesifik Pemeriksaan Identitas}

Pendeskripsian tata nama yaitu nama ekstrak, nama latin tumbuhan, bagian tumbuhan yang digunakan dan nama Indonesia tumbuhan (Depkes RI, 2000).

\section{Pemeriksaan organoleptik}

Yaitu dengan pengenalan secara fisik dengan menggunakan panca indera dalam mendeskripsikan bentuk, bau, warna, rasa, ukuran

\section{Pengujian Kandungan Kimia}

\section{Identifikasi alkaloid}

Sejumlah ekstrak dimasukkan kedalam tabung reaksi, ditetesi dengan $\mathrm{HCl} 2 \mathrm{~N}$, lalu dibagi dalam beberapa tabung reaksi. Tiap tabung ditambahkan dengan masing-masing pereaksi. Pada penambahan pereaksi mayer, positif sejumlah mengandung alkaloid jika membentuk endapan putih atau kuning. Pada penambahan pereaksi wagner, positif mengandung alkaloid jika terbentuk endapan coklat. Pada penambahan pereaksi dragendroff, positif mengandung alkaloid jika terbentuk endapan jingga (Kusumawati, dkk. 2003).

\section{Identifikasi flavonoid}

Sejumlah 0,5 gram ekstrak dimasukkan kedalam tabung reaksi dilarutkan dalam $2 \mathrm{~mL}$ etanol 70\% kemudian diaduk, ditambahkan serbuk magnesium o,5 g dan 3 tetes $\mathrm{HCl}$ pekat. Apabila terbentuk warna jingga sampai merah menunjukkan adanya flavon, merah sampai jingga menunjukkan flavanol, jingga sampai merah keunguan menunjukkan flavanon (Mojab, dkk., 2003) (Kusumawati, dkk., 2003).

\section{Identifikasi saponin}

Sejumlah 0,5 gram ekstrak dimasukkan kedalam tabung reaksi 
ditambahkan $10 \mathrm{~mL}$ air panas, dinginkan kemudian kocok kuat-kuat selama 10 detik. Positif mengandung saponin jika terbentuk busa setinggi 1-10 $\mathrm{cm}$ selama tidak kurang dari 10 menit dan pada penambahan 1 tetes HCL $2 \mathrm{~N}$, busa tidak hilang (Depkes RI, 1995).

\section{Identifikasi tanin}

Sejumlah 0,5 gram ekstrak dimasukkan kedalam tabung reaksi kemudian dikocok dengan air panas hingga homogen setelah itu ditambahkan $\mathrm{FeCl}_{3}$, jika menghasilkan biru karakteristik biru-hitam, berarti mengandung tanin pirogalol. Sedangkan untuk tanin katekol dianggap positif jika pada penambahan larutan $\mathrm{FeCl}_{3}$ maka akan berwarna hijau atau biru-hijau dan endapan (Kusumawati, dkk., 2003).

\section{Identifikasi Terpenoid dan Steroid}

Ekstrak dimasukkan sedikit dalam tabung reaksi kecil, lalu dikocok dengan sedikit eter. Lapisan eter diambil lalu diteteskan pada plat tetes, dan dibiarkan sampai kering. Setelah kering, ditambahkan dua tetes asam asetat anhidrat dan satu tetes asam sulfat pekat. Apabila terbentuk warna orange, merah atau kuning berarti positif terpenoid. Tetapi apabila terbentuk warna hijau berarti positif steroid (Soetamo dan Soediro, 1997; Depkes RI, 2000).

Kadar Senyawa Yang Larut dalam Air

Ekstrak sebanyak 2,5 g (W1) ditimbang, disari selama 24 jam dengan
$50 \mathrm{~mL}$ air kloroform LP menggunakan labu ukur. Kocok sesekali selama 6 jam pertama, diamkan selama 18 jam dan di saring. Filtrat yang diperoleh diuapkan hingga kering dalam cawan dangkal berdasar rata yang telah ditara (Wo) dengan cara didiamkan sampai pelarutnya menguap dan tersisa residunya. Residu dipanaskan pada suhu $105^{\circ} \mathrm{C}$ hingga bobot tetap (W2), hitung kadar dalam \% sari larut air.

\section{Kadar Senyawa Yang Larut dalam} Etanol

Ekstrak sebanyak 2,5 g (W1) ditimbang, dimaserasi dengan $50 \mathrm{~mL}$ etanol 95\% selama 24 jam menggunakan labu bersumbat. Kocok sesekali selama 6 jam pertama, diamkan selama 18 jam dan disaring dengan cepat untuk menghindari penguapan etanol. Filtrat yang diperoleh diuapkan hingga kering dalam cawan dangkal berdasar rata yang telah ditara (Wo) dengan cara didiamkan sampai pelarutnya menguap dan tersisa residunya. Residu dipanaskan pada suhu $105^{\circ} \mathrm{C}$ hingga bobot tetap (W2), hitung kadar dalam \% sari larut etanol.

\section{Pola Kromatogram (KLT)}

Ekstrak etanol daun matoa (Pometia pinnata J.R. \& G. Forst) ditotolkan pada lempeng silica, selanjutnya dielusi dengan fase gerak yang cocok dengan perbandingan tertentu. Hasil penampakan noda dapat dilihat melalui lampu UV $254 \mathrm{~nm}, 366 \mathrm{~nm}$ dan juga dapat menggunakan pereaksi semprot 
$\mathrm{H}_{2} \mathrm{SO}_{4}$ kemudian dihitung nilai $\mathrm{Rf}$ (Depkes, 1989).

\section{Pengujian Parameter Non Spesifik.}

\section{Penetapan Susut Pengeringan}

Ditimbang ekstrak sebanyak $1 \mathrm{~g}$ dan dimasukkan kedalam krus porselin tertutup yang sebelumnya sudah dipanaskan pada suhu $105^{\circ}$ selama 30 menit dan telah ditara. Sebelum ditimbang, ekstrak diratakan dalam krus porselin dengan menggoyangkan krus hingga membentuk lapisan setebal $5 \mathrm{~mm}$ - $10 \mathrm{~mm}$, masukkan kedalam oven, buka tutupnya, keringkan pada suhu $105^{\circ}$ hingga bobot tetap. Dinginkan dalam eksikator. Lakukan replikasi sebanyak 3 kali kemudian dihitung persentasenya (Depkes RI, 2000).

\section{Penetapan Kadar Abu Total}

Sebanyak 1 g ekstrak ditimbang seksama (W1) dimasukkan dalam cawan porselin yang telah dipijarkan dan ditimbang sebelumnya. Pijarkan dalam tanur secara perlahan (dengan suhu dinaikkan secara bertahap hingga $600 \pm$ $25^{\circ} \mathrm{C}$ (Depkes RI, 1980 dalam Arifin, H.,Anggraini, Handayani \& Rasyid, 2006) hingga arang habis. Setelah itu, didinginkan dalam eksikator dan ditimbang hingga bobot konstan (W2). Percobaan dilakukan sebanyak 3 kali dan dihitung kadar abu.

Penetapan Kadar Abu Yang Tidak Larut Dalam Asam

Abu yang diperoleh pada penetapan kadar abu total dididihkan dengan $25 \mathrm{~mL}$ asam klorida pekat selama 5 menit, kumpulkan bagian yang tidak larut asam dipisahkan dengan cara disaring menggunakan kertas saring bebas abu dan residunya dibilas dengan air panas. Abu yang tersaring dan kertas saringnya dimasukkan kembali dalam krus silikat yang sama. Setelah itu ekstrak dipijarkan dengan menggunakan tanur secara perlahan-lahan (dengan suhu dinaikkan secara bertahap hingga $600 \pm 25^{\circ} \mathrm{C}$ (Depkes RI, 1980 dalam Arifin, H.,Anggraini, Handayani \& Rasyid, 2006) hingga arang habis. Kemudian ditimbang hingga bobot tetap (W3).

\section{Bobot Jenis}

Bobot jenis ekstrak ditentukan terhadap hasil pengenceran ekstrak $5 \%$ dalam pelarut etanol dengan alat piknometer. Digunakan piknometer kering, bersih dan telah dikalibrasi dengan menetapkan bobot piknometer dan bobot air yang baru dididihkan pada suhu $25^{\circ} \mathrm{C}$ kemudian ditimbang (W1). Ekstrak cair diatur suhunya kurang lebih $20^{\circ} \mathrm{C}$ lalu dimasukkan ke dalam piknometer kosong, buang kelebihan ekstrak, atur suhu piknometer yang telah diisi hingga suhu $25^{\circ} \mathrm{C}$ kemudian ditimbang (W2).

\section{Kadar Air}

Penetapan kadar air dengan cara destilasi toluen. Toluen yang digunakan dijenuhkan dengan air terlebih dahulu, setelah dikocok didiamkan, kedua lapisan air dan toluen akan memisah, lapisan air 
dibuang. Kemudian ditimbang ekstrak sebanyak $10 \mathrm{~g}$ dan dimasukkan kedalam labu alas bulat dan ditambahkan toluen yang telah dijenuhkan dengan air. Labu dipanaskan hati-hati selama 100 menit, setelah toluen mulai mendidih, penyulingan diatur 2 tetes/detik, lalu 4 tetes/detik. Setelah semua toluen mendidih dilanjutkan pemanasan selama 5 menit. Biarkan tabung menerima dingin hingga suhu kamar. Volume air dibaca sesudah toluen dan air memisah sempurna. Lakukan replikasi sebanyak 3 kali kemudian dihitung persentasenya (Saifuddin, dkk., 2011).

\section{Cemaran Mikroba}

Pada penyiapan sampel sebanyak $1 \mathrm{~g}$ ekstrak dimasukkan ke dalam labu ukur $10 \mathrm{~mL}$ dilarutkan dalam $10 \mathrm{~mL}$ DMSO 10\% dikocok hingga homogen didapatkan pengenceran $10^{-1}$. Disiapkan 3 tabung, lalu masukkan $9 \mathrm{~mL}$ pengencer $10^{-1}$ kedalam tabung pertama, kocok hingga homogen didapatkan pengenceran $10^{-2}$, selanjutnya dilanjutkan dengan pengenceran $10^{-3}$ dan $10^{-4}$ (Volk \& Wheeler, 2013 ; Depkes RI, 2000 ; Saifuddin, dkk.,2011).

\section{Angka Lempeng Total (ALT)}

Dipipet $1 \mathrm{~mL}$ dari tiap pengenceran kedalam cawan petri yang steril (duplo), dengan menggunakan pipet yang berbeda dan steril untuk tiap pengenceran. Ke dalam tiap cawan petri dituangkan $5 \mathrm{~mL}$ media Nutrient Agar yang telah dicairkan bersuhu kurang lebih $45^{\circ} \mathrm{C}$. Cawan petri digoyangkan dengan hati-hati (putar dan goyangkan ke depan dan ke belakang serta ke kanan dan ke kiri) hingga sampel bercampur rata dengan pembenihan. Kemudian dibiarkan hingga campuran dalam cawan petri membeku. Cawan petri dengan posisi terbalik dimasukkan kedalam lemari inkubator suhu $35^{\circ} \mathrm{C}$ selama 24 jam. Catat pertumbuhan koloni pada masing-masing cawan yang mengandung 30-300 koloni setelah 24 jam. Hitung ALT dalam koloni/g sampel dengan mengalikan jumlah rata-rata koloni pada cawan dengan faktor pengenceran yang sesuai (Depkes RI, 2000 ; Saifuddin, dkk., 2011).

\section{Kapang dan Khamir}

Kedalam cawan petri yang steril (duplo) tuangkan $5 \mathrm{~mL}$ media Potato Dextros Agar yang telah dicairkan bersuhu $45^{\circ} \mathrm{C}$, biarkan membeku pada cawan. Pipet 0,5 mL dari tiap pengenceran kedalam cawan petri yang steril (metode semai), dengan menggunakan pipet yang berbeda dan steril untuk tiap pengenceran. Cawan petri digoyangkan dengan hati-hati hingga sampel tersemai secara merata pada media. Kemudian diinkubasikan pada suhu kamar atau $25^{\circ} \mathrm{C}$ selama 7 hari. Dicatat hasil sebagai jumlah kapang dan khamir/g sampel (Saifuddin, dkk., 2011).

\section{HASIL DAN PEMBAHASAN}

Pada penelitian ini digunakan sampel daun matoa (Pometia pinnata J.R. \& G.Forst) yang didapatkan dari kota 
Jayapura. Berdasarkan beberapa penelitian daun matoa memiliki potensi sebagai obat tradisional sehingga perlu dilakukan standardisasi bahan baku ekstrak daun matoa. Adapun tujuan dari standardisasi yaitu untuk menjamin mutu dan keamanan ekstrak tanaman obat. Penetapan standard mutu suatu ekstrak meliputi penetapan organoleptik, kadar senyawa terlarut pada pelarut tertentu, kandungan kimia, pola kromatogram, susut penegering, kadar air, kadar abu total, kadar abu tidak larut asam, bobot jenis dan cemaran mikroba.

Penelitian ini diawali dengan proses ekstraksi daun matoa yang telah dikeringkan dengan metode maserasi. Maserasi merupakan cara ekstraksi yang paling mudah dilakukan dan dalam prosesnya tidak dilakukan pemanasan sehingga menghindari kerusakan dari zat aktif yang terkandung dalam simplisia. Proses maserasi dilakukan menggunakan cairan penyari etanol $70 \%$. Penggunaan etanol $70 \%$ sebagai larutan penyari karena etanol memiliki kemampuan menyari senyawa pada rentang polaritas yang lebar mulai dari senyawa polar hingga nonpolar, tidak toksis dibanding dengan pelarut organik yang lain, lebih mudah diuapkan dengan air, tidak mudah ditumbuhi mikroba dan relatif murah (Saifuddin dkk, 2011).

Simplisia daun matoa sebanyak 400 gram dimaserasi dengan cairan penyari etanol $70 \%$ sebanyak 4 liter dan dilakukan remaserasi dengan jumlah pelarut yang sama. Ekstrak kering yang diperoleh sebanyak 51,9431 gram dengan persen rendamen sebesar 12,98\%. Rendamen ekstrak dihitung dengan membandingkan berat ekstrak kering yang diperoleh terhadap jumlah serbuk simplisia yang digunakan pada proses ekstraksi. Rendemen menggunakan satuan persen (\%), semakin tinggi nilai rendemen yang dihasilkan menandakan nilai ekstrak yang dihasilkan semakin banyak. Ekstrak yang didapatkan kemudian dilakukan pengukuran parameter spesifik dan non spesifik.

Tabel 1. Pemeriksaan Identitas

\begin{tabular}{|c|c|}
\hline Deskripsi & Hasil \\
\hline $\begin{array}{c}\text { Nama Ekstrak Ker- } \\
\text { ing }\end{array}$ & $\begin{array}{c}\text { Pometia pinnata Ex- } \\
\text { tractum }\end{array}$ \\
\hline $\begin{array}{c}\text { Nama Latin Tana- } \\
\text { man }\end{array}$ & Pometia pinnata \\
\hline Bagian Tanaman & Pometia Folium \\
\hline $\begin{array}{c}\text { Nama Indonesia } \\
\text { Tanaman }\end{array}$ & Matoa \\
\hline
\end{tabular}

Pemeriksaan identitas simplisia dan ekstrak bertujuan untuk memberikan identitas obyektif nama secara spesifik (Depkes RI, 2000). Hasil pemeriksaan identitas dapat dilihat pada tabel 1 .

Uji kandungan kimia bertujuan untuk memberikan gambaran awal komposisi kandungan kimia (Depkes RI, 2000). Hasil yang diperoleh dari uji kandungan kimia menunjukkan bahwa ekstrak etanol daun matoa mengandung senyawa alkaloid, flavonoid, steroid, tanin dan saponin. 
Tabel 2. Identifikasi Kandungan Kimia

\begin{tabular}{|c|c|c|c|}
\hline \begin{tabular}{|l|} 
Golongan \\
Senyawa
\end{tabular} & Literatur & Hasil & Ket \\
\hline $\begin{array}{l}\text { Alkaloid } \\
\text { P.Mayer }\end{array}$ & $\begin{array}{l}\text { Endapan } \\
\text { putih }\end{array}$ & Endapan & \\
\hline P.Wagner & Endapan coklat & $\begin{array}{l}\text { Endapan } \\
\text { coklat }\end{array}$ & + \\
\hline P.Dragendor & $\begin{array}{l}\text { Endapan jing- } \\
\text { ga }\end{array}$ & $\begin{array}{l}\text { Endapan } \\
\text { jingga }\end{array}$ & \\
\hline Flavonoid & $\begin{array}{c}\text { Larutan me- } \\
\text { rah, kuning } \\
\text { atau jingga }\end{array}$ & $\begin{array}{l}\text { Larutan } \\
\text { merah }\end{array}$ & + \\
\hline Saponin & $\begin{array}{c}\text { Terbentuk busa } \\
1-10 \mathrm{~cm}\end{array}$ & $\begin{array}{l}\text { Terbentuk } \\
\text { busa }\end{array}$ & + \\
\hline $\begin{array}{l}\text { Steroid/ } \\
\text { Terpenoid }\end{array}$ & $\begin{array}{c}\text { Larutan hi- } \\
\text { jau/ Larutan } \\
\text { merah- } \\
\text { kekuningan }\end{array}$ & $\begin{array}{l}\text { Larutan } \\
\text { hijau }\end{array}$ & + \\
\hline Tanin & $\begin{array}{c}\text { Larutan hijau, } \\
\text { biru atau hi- } \\
\text { jau-hitam }\end{array}$ & $\begin{array}{l}\text { Larutan } \\
\text { hijau ke- } \\
\text { hitaman }\end{array}$ & + \\
\hline
\end{tabular}

Ket : $(-)=$ tidak mengandung senyawa,

$(+)=$ mengandung senyawa

Tabel 3. Hasil Pola Kromatogram

\begin{tabular}{|c|c|c|c|}
\hline \multirow{2}{*}{ Sampel } & \multirow{2}{*}{ Eluen } & \multicolumn{2}{|c|}{ Nilai Rf } \\
\cline { 3 - 4 } & & $\begin{array}{c}\text { UV 365 } \\
\text { nm }\end{array}$ & $\begin{array}{c}\text { UV 254 } \\
\text { nm }\end{array}$ \\
\hline \multirow{4}{*}{ Daun Matoa } & $\begin{array}{c}\text { Kloroform : etil } \\
\text { asetat } \\
\text { (1:9) }\end{array}$ & $\mathrm{R}_{1}=0,94$ & $\mathrm{R}_{1}=0,60$ \\
& $\mathrm{R}_{2}=0,54$ & $\mathrm{R}_{2}=0,47$ \\
& $\mathrm{R}_{3}=0,45$ & $\mathrm{R}_{3}=0,30$ \\
& $\mathrm{R}_{4}=0,34$ & \\
\hline
\end{tabular}

Tujuan dari pengujian KLT yaitu untuk memberikan gambaran awal komposisi kandungan kimia berdasarkan pola kromatogram (Depkes RI, 2000). Analisis dengan menggunakan KLT merupakan pemisahan komponen kimia berdasarkan prinsip adsorbsi dan partisi yang ditentukan oleh fase diam (adsorben) dan fase gerak (eluen). Uji ini dilakukan dengan melakukan orientasi eluen terlebih dahulu dengan tingkat kepolaran yang berbeda untuk mendapatkan pelarut yang mampu memberikan pemisahan yang baik serta noda zat warna yang bagus. Eluen yang baik adalah eluen yang bisa memisahkan senyawa dalam jumlah yang banyak ditandai dengan munculnya noda. Noda yang terbentuk tidak berekor dan jarak antara noda yang satu dan yang lainnya jelas (Harborne, 1987). Dari hasil orientasi didapatkan eluen kloroform : etil asetat (1:9).

Adanya beberapa noda pada ekstrak dengan nilai $\mathrm{Rf}$ yang berbeda secara kualitatif menunjukkan adanya beberapa senyawa yang terkandung dalam ekstrak tersebut. Nilai Rf yang baik berkisar antara 0,2-0,8. Senyawa yang mempunyai nilai Rf besar berarti memiliki kepolaran yang rendah begitupun sebaliknya dikarenakan sifat fase diam yang polar. Senyawa yang lebih polar akan tertinggal pada fase diam sehingga menghasilkan nilai $\mathrm{Rf}$ yang rendah. Jika Rf terlalu tinggi yang harus dilakukan adalah mengurangi kepolaran eluen ataupun sebaliknya (Ewing, 1985). Pengamatan dilakukan pada sinar UV dengan panjang gelombang $254 \mathrm{~nm}$ warna pada noda terlihat hijau dikarenakan plat yang digunakan adalah silika gel GF 254 yang akan berfluoresensi pada panjang gelombang pendek yakni $254 \mathrm{~nm}$ (Rohman, 2009). Pada penyemprotan dengan menggunakan $\mathrm{H}_{2} \mathrm{SO}_{4}$ bertujuan untuk memperjelas noda yang tampak pada lampu UV 254 dan 365 . 
Tabel 4. Hasil Pengukuran Kadar

Senyawa Dalam Pelarut Tertentu

\begin{tabular}{|c|c|c|c|c|c|}
\hline \multirow{2}{*}{$\begin{array}{c}\text { Parame- } \\
\text { ter }\end{array}$} & \multicolumn{3}{|c|}{ Kadar (\%) } & \multirow{2}{*}{$\begin{array}{c}\text { Rerata } \\
\text { (\%) }\end{array}$} & \multirow{2}{*}{ Syarat } \\
\hline & $\mathbf{I}$ & II & III & & \\
\hline $\begin{array}{c}\text { Sari larut } \\
\text { air }\end{array}$ & 26,24 & 34,48 & 35,92 & 32,21 & $\geq 12 \%$ \\
\hline $\begin{array}{c}\text { Sari larut } \\
\text { etanol }\end{array}$ & 42,6 & 31,2 & 41,9 & 38,56 & $\begin{array}{c}\geq 6,7 \\
\%\end{array}$ \\
\hline
\end{tabular}

Parameter senyawa terlarut dalam air dan etanol bertujuan untuk mengetahui jumlah senyawa yang terlarut dalam air (bersifat polar) maupun etanol (bersifat semi polar-non polar) (Saifudin, dkk.,2011). Kedua pelarut ini dan campuran keduanya merupakan cairan pelarut yang diperbolehkan dan memenuhi syarat kefarmasian. Hasil yang diperoleh yaitu sebesar 32,21\% untuk kadar senyawa larut air. Sedangkan untuk kadar senyawa larut etanol sebesar 38,56\%. Penjumlahan hasil kadar sari larut air dan etanol juga memenuhi syarat yaitu tidak melebihi 100\%. Penjumlahan kadar sari larut air dan kadar sari larut etanol suatu ekstrak seharusnya tidak akan lebih dari 100\% (Saifudin, dkk.,2011). Dapat dilihat juga ekstrak lebih banyak terlarut dalam etanol dibandingkan air menunjukkan senyawa aktif dalam ekstrak lebih cenderung mudah tersari dalam etanol dibanding air karena pelarut etanol merupakan pelarut universal sehingga mampu menarik senyawa polar dan non polar sedangkan air hanya mampu menarik senyawa yang bersifat polar.
Tabel 5. Hasil Pengukuran Susut Pengering

\begin{tabular}{|c|c|c|c|c|c|}
\hline \multirow{2}{*}{ Pengujian } & \multicolumn{3}{|c|}{ Kadar (\%) } & \multirow{2}{*}{ Rerata } & \multirow{2}{*}{ Syarat } \\
\cline { 2 - 4 } & I & II & III & (\%) & \\
\hline $\begin{array}{c}\text { Susut Pen- } \\
\text { geringan }\end{array}$ & 7,82 & 6,99 & 6,28 & 7,03 & $\begin{array}{c}\leq 10 \\
\%\end{array}$ \\
\hline
\end{tabular}

Parameter susut pengeringan merupakan pengukuran sisa zat setelah pengeringan pada temperatur $105^{\circ} \mathrm{C}$ selama 30 menit atau sampai berat konstan yang dinyatakan sebagai nilai persen. Dengan mengetahui susut pengeringan dapat memberikan batasan maksimal tentang besarnya senyawa yang hilang pada proses pengeringan (Depkes RI, 2000). Nilai susut pengeringan yang diperoleh dari ekstrak daun matoa adalah sebesar 7,03\%. Hal ini menunjukkan besarnya kadar air dan senyawa-senyawa yang hilang selama proses pengeringan adalah 7,03\%. Persyaratan yang baik untuk susut pengeringan adalah kurang dari 10\%, karena susut pengeringan juga mewakili kandungan air yang yang menguap.

Tabel 6. Hasil Pengukuran Kadar Air

\begin{tabular}{|c|c|c|c|c|c|}
\hline \multirow{2}{*}{ Pengujian } & \multicolumn{3}{|c|}{ Kadar (\%) } & Rerata & \multirow{2}{*}{ Syarat } \\
\cline { 2 - 4 } & I & II & III & (\%) & \\
\hline Kadar Air & 5 & 5 & 5 & 5 & $<10 \%$ \\
\hline
\end{tabular}

Penetapan kadar air dilakukan untuk menetapkan residu air setelah proses pengentalan atau pengeringan. Hasil penetapan kadar air ekstrak daun matoa sebesar 5\%. Range kadar air tergantung jenis ekstrak, untuk ekstrak kering kadar air <10\% (Voight, 1995). Kadar air menentukan stabilitas suatu ekstrak, 
biasanya kadar air yang berisiko adalah lebih dari 10\% (Saifudin, dkk.,2011).

Tabel 7.Hasil Pengukuran Kadar Abu

\begin{tabular}{|c|c|c|c|c|c|}
\hline $\begin{array}{c}\text { Pen- } \\
\text { gujian }\end{array}$ & \multicolumn{3}{|c|}{ Kadar (\%) } & \multirow{2}{*}{$\begin{array}{c}\text { Rerata } \\
\text { (\%) }\end{array}$} & $\begin{array}{c}\text { Syara } \\
\text { t }\end{array}$ \\
\cline { 2 - 4 } & I & II & III & (\%) & $\leq 10,2 \%$ \\
$\begin{array}{c}\text { Kadar } \\
\text { abu to- } \\
\text { tal }\end{array}$ & 2,39 & 2,09 & 2,91 & 2,46 & \\
\hline $\begin{array}{c}\text { Kadar abu } \\
\text { tidak larut } \\
\text { asam }\end{array}$ & 0,077 & 0,040 & 0,030 & 0,049 & $\leq 2 \%$ \\
\hline
\end{tabular}

Penentuan kadar abu dilakukan untuk memberikan gambaran kandungan mineral internal dan eksternal yang berasal dari proses awal sampai terbentuknya ekstrak. Pada tahap ini ekstrak dipanaskan hingga senyawa organik dan turunannya terdestruksi dan menguap sampai tinggal unsur mineral dan anorganik saja sedangkan untuk penetapan kadar abu yang tidak larut asam dimaksudkan untuk mengevaluasi ekstrak terhadap kontaminasi bahanbahan yang mengandung silika seperti tanah dan pasir.

Kadar abu total yang diperoleh dari ekstrak daun matoa sebesar 2,46\% sedangkan untuk kadar abu tidak larut asam sebesar 0,049\% juga memenuhi syarat WHO yaitu tidak boleh lebih dari $2 \%$.

Kadar abu hendaknya mempunyai nilai kecil karena parameter ini menunjukkan adanya cemaran logam berat yang tahan pada suhu tinggi (Isnawati dan Arifin, 2006).
Tabel 8. Hasil Pengukuran Bobot Jenis

\begin{tabular}{|c|c|c|c|c|c|}
\hline \multirow{2}{*}{ Parameter } & \multirow{2}{*}{ Sampel } & \multicolumn{3}{|c|}{ Replikasi sampel } & \multirow{2}{*}{$\begin{array}{c}\text { Rerata } \\
(\mathbf{g} / \mathbf{m L})\end{array}$} \\
\cline { 3 - 5 } & I & II & III & \\
\hline $\begin{array}{c}\text { Bobot } \\
\text { jenis }\end{array}$ & $\begin{array}{c}\text { Daun ma- } \\
\text { toa }\end{array}$ & 0,903 & 0,8949 & 0,906 & 0,9013 \\
\hline
\end{tabular}

Bobot jenis diartikan sebagai perbandingan kerapatan suatu zat terhadap kerapatan air dengan nilai masa persatuan volume. Penentuan bobot jenis bertujuan untuk memberi batasan tentang besarnya massa persatuan volume yang merupakan parameter khusus ekstrak cair sampai menjadi ekstrak kental yang masih dapat dituang, bobot jenis juga terkait dengan kemurnian ekstrak dari kontaminasi (Depkes RI, 2000). Ekstrak yang digunakan adalah ekstrak kental yang diencerkan $5 \%$ terlebih dahulu dengan etanol $70 \%$ sebagai pelarut. Hasil dari pengukuran bobot jenis ekstrak etanol daun matoa yaitu $0,9013 \mathrm{~g} / \mathrm{mL}$.

Tabel 9. Hasil Pengukuran Cemaran Mikroba

\begin{tabular}{|c|c|c|}
\hline Parameter & $\begin{array}{c}\text { Hasil (ko- } \\
\text { loni/g) }\end{array}$ & $\begin{array}{c}\text { Syarat (ko- } \\
\text { loni/g) } \\
\text { Dirjen POM }\end{array}$ \\
\hline $\begin{array}{c}\text { Cemaran bak- } \\
\text { teri }\end{array}$ & $8,2 \times 10^{4}$ & $1 \times 10^{6}$ \\
\hline $\begin{array}{c}\text { Cemaran ka- } \\
\text { pang }\end{array}$ & $1,7 \times 10^{3}$ & $1 \times 10^{4}$ \\
\hline
\end{tabular}

Pengujian ini bertujuan untuk mengetahui jumlah mikroorganisme yang diperoleh dan untuk menunjukkan ada tidaknya bakteri tertentu dalam ekstrak. Pada ekstrak daun matoa terdapat cemaran bakteri sebesar 8,2 x $10^{4}$ koloni/g dan cemaran kapang/khamir sebesar $1,7 \times 10^{3} \mathrm{koloni} / \mathrm{g}$. Menurut SK 
Dirjen POM No : 03726/B/SK/VIII/89, ini berada dibawah batas maksimum yaitu $10^{6} \mathrm{koloni} / \mathrm{g}$ un tuk bakteri dan $10^{4}$ koloni/g untuk kapang. Rendahnya pertumbuhan bakteri ini juga bisa disebabkan karena ekstrak yang digunakan adalah ekstrak etanol yang dapat menghambat pertumbuhan bakteri atau mikroba dalam ekstrak. Pada kontrol media juga tidak ditumbuhi bakteri dan jamur yang berarti bahwa tidak ada kontaminan dari media yang digunakan.

\section{KESIMPULAN}

Dari hasil penelitian yang dilakukan dapat ditarik kesimpulan sebagai berikut

Pada pengujian parameter spesifik ekstrak etanol daun matoa didapatkan identitas ekstrak dengan pengamatan organoleptik ekstrak kering berwarna coklat, berbau khas dan memiliki rasa yang pahit. Ekstrak etanol daun matoa mengandung senyawa alkaloid, flavonoid, tanin, saponin dan steoid. Kandungan senyawa dalam ekstrak yang larut di dalam air $32,21 \%$ sebesar dan senyawa larut dalam etanol sebesar $38,56 \%$ hasil ini memenuhi persyaratan.

1

Pada pengujian non spesifik ekstrak etanol daun matoa didapatkan hasil susut pengeringan sebesar 7,03\%. Bobot jenis sebesar 0,9013 g/mL. Kadar abu total sebesar 2,46\% dan kadar abu tidak larut asam sebesar 0,049\%. Kadar air sebesar $5 \%$. Cemaran bakteri sebesar $8,2 \times 10^{4}$ koloni/g dan cemaran kapang sebesar $1,7 \times 10^{3}$ koloni/g. Hasil pengujian parameter nonspesifik telah memenuhi persyaratan ekstrak yang telah ditetapkan oleh Depkes RI dan WHO.

\section{SARAN}

Perlu dilakukan penelitian parameter spesifik dan non spesifik yang lainnya.

\section{DAFTAR PUSTAKA}

BPOM RI, 2011, Taksonomi Koleksi Tanaman Obat Kebun Tanaman Obat Citeureup, Volume Ketiga, Direktorat Obat Asli Indonesia : Jakarta. P.84

BPOM RI, 2011, Acuan Sediaan Herbal. Badan Pengawas Obat Dan Makanan : Jakarta, P.107

Dalimartha S, Adrian F., 2005, Makanan dan Herbal Untuk Penderita Diabetes Melitus, Jakarta: Penabur Swadaya

Departemen Kesehatan RI, 2000, Parameter Standar Umum Ekstrak Tumbuhan Obat, cetakan pertama, Direktorat Jenderal Pengawasan Obat dan Makanan, P.10-12 : Jakarta

Departemen Kesehatan RI, 1989, Materia Medika Indonesia, Jilid $V$, Departemen Kesehatan Republik Indonesia : Jakarta

Departemen Kesehatan Republik Indonesia, 1980, Materia Medika Indonesia, Jilid IV, Jakarta: Direktorat Pengawasan Obat dan Makanan, P.77, 185

Ditjen POM, 1995, Materia Medika Indonesia, Departemen Kesehatan Republik Indonesia : Jakarta

Harborne, J.B, 1987, Metode Fitokimia: Penuntun Cara Modern Menganalisa Tumbuhan, Penerbit ITB : Bandung 
Isnawati, A.,dan Arifin K.M. 2006. Karakterisasi Daun Kembang Sungsang (Gloria superba L) dari aspek Fitokimia. Media Litbang Kesehatan, 16(4), 8-14

Kusumawati, I., Djatmiko, W., dan Rahman, A. Studiawan, H., Ekasari, W. 2003. Eksplorasi Keanekaragaman dan Kandungan Kimia Tanaman Obat di Hujan Tropis Gunung Arjuno. Jurnal Bahan Alam Indonesia, 2(3): 100104

Mojab F, Kamalinejad M, Naysaneh G. \& Hamid RV, 2003, Phytochemical Screening of Some Species of Iranian Plants, Iranian Journal of Pharmaceutical Research. 2003, 7782

Rahimah., Endah, S., dan Afghani Jayuska, 2013, Karakterisasi Senyawa Flavonoid Hasil Isolat Dari Fraksi Etil Asetat Daun Matoa (Pometia pinnaata J.R.Forst \& G.Forst). Fakultas MIPA. Universitas Tanjungpura.

Saifuddin, A., Rahayu, V., dan Teruna, H., Y, 2011, Standarisasi Bahan Obat Alam. Graha Ilmu : Yogyakarta

Sangat HM et al, 2000, Kamus Penyakit dan Tumbuhan Obat Indonesia (Etnofitomedika), Jakarta: Yayasan Obor Indonesia

Sudarmono, 2000, Matoa (Pometia pinnata). Keragaman Jenis dan Potensi. Proseding Seminar Sehari Menggali Potensi dan Meningkatkan Prospek Tanaman Hortikultura Menuju Ketahanan Pangan. Kebun Raya Bogor, LIPI.

Variany G, 1999, Isolasi dan Identifikasi Flavonoid dari Daun (Pometia pinnata) [skripsi]. Yogyakarta: Fakultas Farmasi, Universitas Gajah Mada.

Voight, R. 199,. Buku Pelajaran Teknologi Farmasi. Gadjah Mada University Press : Jogjakarta .
Volk \& Wheeler, 2013, Mikrobiologi Dasar Jilid 1 Edisi Kelima. Erlangga : Jakarta. 